\title{
UN PROFETA POLÍTICO: JOAQUÍN COSTA *
}

\author{
JAVIER VARELA \\ Universidad Nacional Educación a Distancia
}

Joaquín Costa era hijo de propietarios rurales muy pobres. Aunque nacido en Monzón, en 1846, su familia se trasladó muy pronto a Graus, provincia de Huesca, su lugar de procedencia original. Una región, la del Alto Aragón, donde eran harto visibles las supervivencias de la sociedad agraria tradicional. El padre de Costa era, al parecer, buen conocedor del derecho consuetudinario aragonés, y solia ejercer de mediador en las disputas locales. Una tierra la oscense de reciente pasado carlista. En 1835 las tropas del Pretendiente fueron recibidas con júbilo en Huesca; y en Barbastro también entraron sin dificultad alguna. Los primeros biógrafos de Costa hablan del «elemento místico, clerical» de su familia; del «medio levítico» en el que fue educado. Una numerosa familia la suya, con varios sacerdotes. Uno de ellos, su tío José Salamero, fue una personalidad dentro de la Comunión Tradicionalista.

La juventud y adolescencia de Costa fueron, más que difíciles, patéticas. Tuvo que conjugar distintos oficios manuales - labrador, jabonero, albañil, palafrenero y medio criado - con estudios hechos a la buena de Dios, en la escuela de primeras letras de Graus y en el instituto de Huesca. De hecho, su primera salida a Europa, a la Exposición de París de 1867, fue posible merced a una pensión oficial concedida a título de albañil. Sus estudios en Madrid, porfiados, voraces, heterogéneos, se realizaron en medio de la más negra miseria. Viviendo en pensiones lúgubres, casi de prestado, repartiendo sablazos

\footnotetext{
* Nota del director: En conmemoración del sesquicentenario del nacimiento de Joaquín Costa cele esta nota apareció en el Boletín de la Institución Libre de Enseñanza (diciembre 1996).
} 
entre amigos y parientes, visitante asiduo de las casas de empeño y de los fonduchos de abono. Las notas autobiográficas que redacta en estos años, En este valle de lágrimas, dan cuenta de un penoso vivir: sin camisa que ponerse ni pantalón decente; con sólo dos botas del mismo pie, teniendo que remojar una de ellas por la noche, para darle la debida flexibilidad y poder calzársela. Su obstinación lectora - furiosa pasión autodidacta - logra el objetivo de doctorarse sucesivamente en Derecho y Filosofía y Letras. La frecuentación de las clases de Giner de los Ríos, desde 1871, resultó fundamental. Desde 1878 tomó parte activa en los trabajos de la recién creada Institución Libre de Enseñanza. Entre 1880 y 1883 dirige el Boletín de la Institución, dejando constancia de una erudición un tanto desordenada, pues lo mismo publicaba sobre temas de química o historia, que sobre pedagogía y el cultivo de los cereales. Quede como ejemplo el título de un artículo de 1882, publicado en colaboración: «El agua caliente en el tratamiento de las hemorroides y del reumatismo». Fracasado en las oposiciones a la cátedra de Historia de España de la Central, también perderá en el mismo año de 1875 el premio extraordinario de Filosofía; una lum. brera en alza le arrebata este último: Menéndez Pelayo. Apenas si logró salir de la inopia económica sacando plaza de letrado en la Administración económica. Sólo en 1889, al ganar las oposiciones a notario, alcanzó una situación que, por otra parte, nunca fue desahogada.

Las primeras actividades públicas de cierta nota las realizó Costa como miembro de la Sociedad de Geografia Colonial y Mercantil, en 1883, y de su heredera, la de Africanistas y Colonialistas, en 1884. Más tarde, coincidiendo con la crisis agudísima de la agricultura de cereal en Aragón, vendrá la época de las campañas agrarias, con la fundación de la Liga de Contribuyentes de Ribagorza (1891), y de la Cámara Agrícola del Alto Aragón (1892). El desastre de 1898 supuso su entrada en la política nacional. El estupor que sigue a la derrota, el descrédito del Estado y de los partidos, crearon un clima propicio en el que medraron las representaciones corporativas. Primero, la Asamblea de las Cámaras; luego la creación, bajo impulso costista, de la Liga Nacional de Productores (Zaragoza, febrero de 1899), a la que se asociaron representaciones agrarias de toda España. Estas reuniones y programas de regeneración fueron, por lo general, favorablemente acogidos por los medios de opinión y por los hombres políticos. Costa se convirtió entonces en el hombre que, junto con Basilio Paraíso y Santiago Alba, encarnaba las aspiraciones de las llamadas «clases productoras». La subida al poder de los conservadores, en 1899, con la estabilización presupuestaria de Villaverde, trocó el amago de colaboración en enfrentamiento abierto. Las Cámaras y la Liga, fusionadas en la Unión Nacional, en 1990, orientaron su protesta contra el recargo de impuestos, aunque 
con un programa de «regeneración» global. El choque con el gobierno Silvela tuvo por consecuencia la derrota del movimiento gremial, después de llamar al cierre de comercios y la desobediencia fiscal.

Una vez demostrada la impotencia de los gremios para desafiar al Estado de la Restauración, Joaquin Costa se tomó un respiro para llevar a cabo la encuesta sobre Oligarquía y Caciquismo, además de preparar un discurso de ingreso en la Academia de C.C. Morales y Políticas. A principios de 1903 decidió pasar al campo republicano, seguido fielmente por la Cámara Altoaragonesa. Una breve adscripción política que, como todas sus empresas, resultaria efímera. La retirada a Graus fue la consecuencia del fracaso. Viviendo de una corta renta, Costa se dedicó a rumiar su desventura, a sufrir impotente los avances de un enfermedad crónica - distrofia muscular- y a realizar fugaces incursiones a Madrid. Los apasionados del personaje le veían entonces inclinado en su pupitre del Ateneo, entre pilas de libros, escribiendo papeletas con su letra menuda; o le visitaban los jueves y domingos, en un oscuro entresuelo de la calle de Los Madrazo; esa casa triste que, según Azorín, siempre olía a aceite frito. Su muerte, en febrero de 1911, seguida de una ridícula disputa por el cadáver, suscitó una rara unanimidad. Convertido en una gloria nacional, todos los partidos, todos los grupos y personalidades confesaron deberle algo. Quién, el fervor tradicionalista; quién, el europeísmo; algunos, la política hidráulica; otros, sus audaces propuestas agraristas. En la admiración por el león de Graus, por el Fichte español, coincidieron republicanos y dinásticos, liberales y carlistas, la ILE y el Correo Español, Antonio Maura y Canalejas, Julio Cejador y Unamuno... En fin, cuando menos se dijo que habia sido «todo un carácter».

Esta contradictoria unanimidad continuó por largos años. El general Primo de Rivera inauguró un monumento en Graus, en septiembre de 1929, llamándolo «gran patriota y vidente»; declarando que su programa nacional era el del gobierno que él presidía. El dictador español gustaba referirse a los politicos desplazados como «locos, burros y cobardes», lo mismo que su «maestro»; política hidráulica era la de su ministro Guadalhorce, y él mismo, al fin y al cabo, era un paternal «cirujano de hierro». Claro está que la izquierda lo reclamó como suyo, lo mismo que había hecho con Gavinet en $1924 \ldots$ La ambigüedad de Costa se prolongó hasta nuestros días, dividiendo a los intérpretes: desde el prefascista, dibujado apresuradamente por Tierno Galván, al crítico del liberalismo apellidado «burgués»; desde el predecesor del «Estado de obras», en la terminología de Gonzalo Fernández de la Mora, al evocador de «potenciales sugerencias revolucionarias», entrevisto por algún exégeta. Un autor, Costa, siempre bienquisto entre la derecha antiparlamentaria tanto como entre la izquierda populista y antiliberal. 
Hace tiempo que el publicista Luis Bello apreció en 1898 un hito en la evolución de Costa. Hasta entonces se había dedicado a restablecer la autenticidad nacional. Era la fase casticista. Luego se propondrá regenerar España de acuerdo con el molde europeo. Así lo vieron también Ortega y Gasset y Ramiro de Maeztu, empeñados por entonces en una cruzada europeísta. Más cerca de nosotros, se advirtió que, desde 1898, Costa entraba en una fase directamente política, de crítica rotunda al régimen político español. Sin desdeñar lo que hay de acertado en estos intentos de periodización, a nuestro juicio, Joaquín Costa permaneció firme en unas cuantas orientaciones y creencias básicas, antes y después del 98, que pueden sintetizarse en cuatro puntos: 1) el tradicionalismo y el casticismo; 2) la teología política; 3) el populismo, y 4) el moralismo antipolítico.

1) El joven Costa asimiló, y de manera duradera, buena parte de las doctrinas del tradicionalismo español. Si no la fidelidad al pretendiente carlista, sí que existe una gran semejanza con los temas de la contrarrevolución. La búsqueda afanosa del ideal perdido, cuando reinaba la armonía social y no habia Estado que la perturbase con sus legalidades abstractas, es lo que caracteriza a Costa. Ese ideal lo busca en los años ochenta en el folklore popular; en los noventa, en los volúmenes dedicados al colectivismo agrario: ejercicio de resurrección de las tradiciones comunitarias, a la vez que crítica rotunda del liberalismo desamortizador. Lo busca a través de sus investigaciones sobre derecho consuetudinario. Lo busca con desesperación al producirse el desastre del 98. Por eso tratará, una y otra vez, de «recuperar el hilo roto de la tradición». Si algo va mal en el mundo, o en la historia o en el presente español, es porque alguien o algo, sin duda maléfico, interrumpió artificialmente el suave fluir de los siglos. El responsable será, en su juventud, la romanización, anuladora del sustrato celtibero. Luego la monarquía absoluta, que alteró la unidad espontánea entre la aristocracia y el pueblo, elevando por encima de ellos una vida de artificio. Luego, el individualismo económico liberal, que desamortizó la propiedad vinculada en beneficio de los ricos, descomponiendo la vida de la comunidad campesina. Responsable fue también el llamado liberalismo doctrinario (anfibologia krausista que designa el constitucionalismo liberal), que eclipsó la vieja doctrina española, la de tratadistas como Covarrubias, Mariana o Suárez, que trastornó la constitución interna, suplantándola por otra, artificiosa y vana.

La modernidad es siempre catastrófica. Esas cosas odiosas, dirá en 1901, que se llaman teléfono, ferrocarril, prensa y parlamento, que «mantienen al sistema nervioso en vibración constante, fuera de sí, lindero al manicomio». Lo que Costa anunciaba en 1898, de manera perentoria, era la bancarrota del liberalismo in toto, no solamente la del Estado de la Restauración. Si España ha 
decaído, si es una nación frustrada, dirá entonces, se debe a que los españoles no supieron darse una constitución propia, adecuada a su psicologia y suelo, con instituciones creadas por la espontaneidad social. Se debe, repite en 1906, a que la vestimenta constitucional-liberal es inadecuada a la morfología especial de España, a su autenticidad, y, gran reproche tradicionalista, a que está copiada de otros países.

2) Joaquín Costa parece haber pasado de una creencia católica ortodoxa, en sus tiempos mozos, a un cristianismo que se desea filosófico y tolerante. El anticlericalismo subirá de tono a principios de siglo, en el momento del pleito de La Solana (disputa por un legado benéfico entre esa población y el cabildo de Ciudad Real). Pero esto no desmiente su religiosidad esencial; la religiosidad de un cristiano sin iglesia.

Religión política o política religiosa, el relato biblico es el prototipo de la actuación secular. Jesús de Nazaret es el modelo de estadistas. Es el «cirujano de hierro» que, armado de látigo, arroja a los mercaderes del templo, es decir, cruza la cara de los políticos. Cristo es España; su pasado, su presente y su porvenir son momentos de un via crucis. repartida en trozos entre las potencias, «como los soldados la túnica de Cristo»; consintiendo en su muerte - su derrota-, e imprecando a su Padre por haberla abandonado. El pais toma animosamente su cruz, pero el Cirineo gubernamental, en lugar de auxiliarle, se queda en casa. España está clavada en el madero por los miserables lacayos de los políticos (1906). Por fín, como Jesús, resucitará al tercer día (1898), etc.

El propio Joaquín Costa, personaje inmensamente egocéntrico, Mesias vocacional, moldeó su identidad personal y el sentido de su obra con arreglo a modelos bíblicos. El empleo obsesivo de la religión, haciendo las veces de reflexión política, creaba un marco apocalíptico inseparable de sus visiones. Lo que profetiza es la inminencia del fin de España; un profeta que, infructuosamente, conjura con su palabra los acontecimientos. Es Moisés, que sueña con otorgar a su rey las tablas de la ley novisima. Es Sansón, que dice abrazarse a las columnas del templo. En fin, al igual que España, a la que encarna, es el propio Cristo, que ilustra con sus sufrimientos el drama de la pasión española.

Podrá decirse, acaso, que todas estas referencias a las Escrituras son artificios retóricos, maneras de levantar las emociones del auditorio, de hacer asequible nociones complejas a gentes saturadas de cultura católica. Hasta cierto punto, esto ocurría así. Lo que asombra, sin embargo, es la reiteración maniática de frases, parábolas y figuras biblicas; recursos empleados ante todo género de oyentes, ya fueran los sencillos labradores de Medina de Rioseco o los asiduos del salón de conferencias del Congreso. Algo que va más allá de la retórica efectista, de la escenificación y del discurso demagógico; algo que sólo pue- 
de nacer de una conciencia religiosa tan honda que llevaba a no diferenciar la historia sagrada de la historia profana.

3) Con el populismo ruso tiene Costa más de una semejanza: la que se deriva, sobre todo, de las fuentes románticas comunes, de la escuela histórica. Los primeros populistas se proponían tomar del pueblo sus canciones, su mitología, su folklore, devolviéndoselo en forma accesible y elaborada; uniendo los fragmentos que representaban al alma popular. Eso es lo que Costa intentó, formando con los refranes y romanceros un tratado de política, mucho más sabia, a su entender, que la ciencia política intelectual y abstracta. La apología populista de la obschina o comunidad campesina rusa, es paralela a la que el español realiza en su Colectivismo agrario. En 1901 propondrá expresamente el mir ruso como ideal agrario: posesión colectiva de todas las tierras del término municipal, y su reparto por sorteo entre los vecinos. Como sus homólogos rusos, el populista Costa pone en el pueblo el origen de la verdad y del bien. Y tanto, que el pueblo es el mismo Cristo, que redime con sus dolores la culpa de los gobernantes.

Pero Costa es, además, un populista en otro sentido: cuando intenta eliminar todas las instituciones representativas que median entre el pueblo y el gobierno. El odio a la política, a esa política «que todo lo ensucia con su asquerosa baba», es otro de los hilos nunca rotos que explica la actividad del aragonés. En lugar de Parlamento y política parecia haber algo que, como la costumbre, era conforme a la supuesta tradición española: el caudillo, el dictador. Costa creyó ver resumida esta aspiración popular y antipolítica en la figura del Cid: encarnación directa de la colectividad, simbolo de la concordia, de la armonía, de la unidad orgánica de la nación. La figura justiciera del Cid será tratada varias veces por él, elevándola a la categoría de mito regeneracionista. Cuando, luego de 1898, pronuncie la frase «doble llave al sepulcro del Cid», se referirá al final de las aspiraciones heroico-caballerescas, las que había fomentado años atrás con sus visiones de grandeza colonial. El entierro del guerrero medieval no pone fin a la necesidad del caudillo salvador. El Cid tiene amplia descendencia en todos los gobernantes autoritarios y antipoliticos que en España han sido: los Reyes Católicos, Cisneros, Aranda, etc. Algunos ejemplares extranjeros hacen compañía a los anteriores: Cromwell, Colbert, Bismarck. Gobernantes con mano de hierro, que no se embarazan con formalidades legales, con «tiquis miquis» constitucionales. Se comprende que el Cirujano de hierro los reseña a todos. Una figura construida con modelos del pasado, sacada casi de algún Espejo barroco para príncipes, muy alejados del jefe político moderno, de tipo carismático.

4) El término de antipolítica ha sido empleado para designar toda activi- 
dad política cuyo enfoque es básicamente moralista. Moralista es Joaquín Costa, que suplanta todos los conceptos políticos por categorias morales. El gobernante ideal, cirujano o tutor, se distingue ante todo por sus cualidades personales, éticas, sustanciales, al margen de cualesquiera formas de Estado o de gobierno, accidentales. Él atesora, como Colbert, fuerza de voluntad, resistencia física, tenacidad. Un tutor, hecho a imagen de Aranda, debería poseer sentimientos de piedad, simpatía y conmiseración por los débiles y los caidos. El político antipolítico se define por su acción personal, por su «acción directa», a espaldas de todo género de institución. Él hace obras de misericordia. Lo suyo es la moralidad del cristianismo: dar de beber al sediento, consolar al triste, vestir al desnudo. El tutor promulga mandamientos, no leyes; mandamientos o programas que acaban por resumirse en dos, como los del decálogo: escuela y despensa. Si los políticos nunca encuentran gracia a los ojos severos de Costa se debe a su cerrazón ante este tipo de soluciones morales; a que no se arrepienten de sus pecados, a que no manifiestan propósito de enmienda, a que dejan al pueblo sin fe, engañándolo cruelmente en sus esperanzas de redención.

Con todo su contradictorio bagaje de doctrinas tradicionales, populistas, teológicas y antipolíticas - aparte de un carácter endiablado-, es comprensible que Joaquín Costa no se caracterizase por su habilidad ni por su perspicacia política. Su fe en la eficacia mágica de la profecía se daba de bruces, una vez y otra, con la pecaminosa realidad. Organizó la Cámara del Alto Aragón en 1893 para dimitir a las pocas semanas: «que haga ahora otro de Cirineo» y «yo me vuelvo a mi sepulcro», fijando así el modo de su acción política, hecha de síncopes. Declaró abominable todo el vocerio patriotero anterior a 1898; una mitología de valentón o de hidalgo viejo que él, con sus campañas colonistas de los años ochenta, había contribuido a forjar. Quien propugnaba una «política impersonal» dio muestras subidas de autoritarismo: al convocar las Cámaras en Zaragoza, concediendo y retirando palabras a su albedrio, desoyendo las protestas tumultuarias, prohibiendo expresamente el trabajo de los delegados en comisión...por ser cosa de parlamentarios. El programa que de alli salió sólo podía ser una amalgama de medidas incoherentes, absolutas las unas (reorganización total e instantánea del Estado, de la Hacienda, del Ejército, de la Agricultura, etc.), las otras nimias y de escaleras abajo (precio del sello de correos, reglamentación del peso del paquete postal); una superposición de orientaciones ultraliberales e intervencionistas, revolucionarias en la forma y reaccionarias en el fondo. Por lo demás, los sucesivos programas costistas siempre son autocontradictorios, lo menos gacetables que concebir se pueda: de un lado, presupuesto raquítico para un Estado casi inexistente; de otro, establecimiento de un sis- 
tema de beneficencia universal a cargo de fondos públicos y, por supuesto, todo ello al margen de las cifras. Del dilema planteado a las organizaciones gremiales -o convertirse en Liga o formar un partido nacional-, no logró ni lo uno ni lo otro, dejando pasar el momento propicio y la expectación que suscitó el movimiento. Costa y las Cámaras se parecen a un ciego guiando a otro ciego. Pero la culpa de los fracasos siempre era de otros: de Basilio Paraíso, de Salmerón, del personalismo de los políticos republicanos, de los políticos o de la nación española que no le escuchaba. A momentos de radicalización, como los de 1899, suceden otros de insólita moderación, en 1990; amenazar primero con visiones terribles, y luego escandalizarse porque unos cuantos comerciantes decidieron no pagar impuestos. La retórica incendiaria - la de las sogas y los cuchillos- suele envolver objetivos modestos: un canal. Pequeñas causas - caida en la exportación de vinos, por ejemplo- siempre producen efectos tremendos: el fin de España. Toda la parafernalia jacobina - los recuerdos de la Convención y 1793 - para resucitar los gremios y la propiedad amortizada, o sea, el Antiguo Régimen, o algo peor que éste: una sociedad agraria, mitad convento - la «congrua sustentación» universal-, mitad cuartel - la «férrea disciplina social»-, la más precisa encarnación de lo que Menéndez Pelayo llamara la «democracia frailuna». Ensalzar al pueblo como materia prima desaprovechada por gobernantes incapaces, niño inocente secuestrado y engañado por bribones, para denigrarlo según las ocasiones como un ser abyecto, atrasado, sucio e ineducado, habitante de la Edad del Bronce. Señalar unas veces al gobierno de oligarcas y caciques como obstáculo a eliminar, la «España oficial»-, para que surgiese espontánea la «España real» del noble pueblo del dos de mayo, o de 1868; desesperar otras de las razas indolente y del suelo áspero, doble maldición eterna. $Y$ ambas determinaciones del pueblo, positivas y negativas, no solamente se suceden en el esquema costista, como la distancia que va entre un presente inerte y un futuro de vida, resultado de hacer pasar al pueblo por la escuela y la despensa. No; el pueblo es Dios - la costumbrey el diablo - la raza maldita. Impugnar el caciquismo para defender de cuando en cuando la necesidad de un encasillado nacional. Fiarlo todo en la prerrogativa regia -entre 1898 y 1900 - y pasar, despechado, a un violento antimonarquismo. Avizorar un apocalipsis republicano en 1903, para declarar a los pocos meses la «pérdida de la fe», y vuelta otra vez al yermo. Pregonar que el abuso de los discursos era el peor de los males nacionales - la «glosocracia»-, y ser un retórico impenitente, eterno forjador de frases. Profeta fracasado, mesías sin pueblo, al fin y al cabo. 